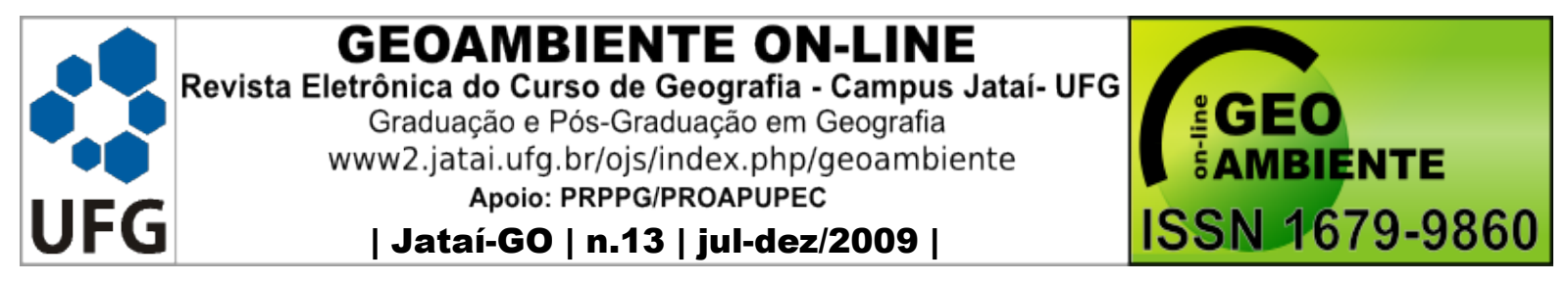

\title{
AVALIAÇÃO DA REFLECTÂNCIA ESPECTRAL DE CORPOS D'ÁGUA EM SANTA MARIA-RS POR MEIO DE ESPECTRORRADIOMETRIA DE CAMPO
}

Aline Batista Ferreira ${ }^{1}$, Waterloo Pereira Filho ${ }^{2}$

(1 - Universidade Federal de Uberlândia,Doutoranda em Geografia (UFU), alineb_ferreira@yahoo.com.br, 2 - Universidade Federal de Santa Maria, Bolsista Produtividade 2 do CNPq, Professor Adjunto do Curso de Geografia e Pós-Graduação, waterloopf@gmail.com)

\section{Resumo}

A pesquisa teve como objetivo avaliar a reflectância espectral dos corpos d'água de três subbacias hidrográficas(arroio Cadena e dos rios Vacacaí-Mirim e Ibicuí-Mirim), localizadas na região central do Rio Grande do Sul/Brasil. As medidas radiométricas foram realizadas com o espectrorradiômetro FieldSpec3 (intervalo espectral de 400 a 900nm e resolução espectral variando de $3 \mathrm{~nm}$, as coletas foram executadas nos dias 30/11/2007 e 07/12/2007. Os corpos avaliados apresentaram baixa refletância. As concentrações de TSS no rio Vacacaí-Mirim $(23,35 \mathrm{mg} / \mathrm{l})$ influenciaram a reflectância e a elevada concentração de matéria orgânica na superfície, este apresentou valores mais expressivos de reflectância que as sub-bacias do arroio Cadena $(9,65 \mathrm{mg} / \mathrm{l})$ e do rio Ibicuí-Mirim $(2,55 \mathrm{mg} / \mathrm{l})$ na faixa de comprimento de onda do verde (entre $500 \mathrm{~nm}$ e $600 \mathrm{~nm}$ ).

Palavras-Chave: reflectância espectral, TSS, sub-bacias, radiometria.

\section{Abstract}

\section{EVALUATION TEHE SPECTRAL REFLECTANCE OF WATER BODIES IN SANTA MARIA -RS THROUGH SPECTRORADIOMETER SANTA MARIA- BRAZIL}

The study aimed to evaluate the spectral reflectance of the water bodies of three watersheds (Cadena Creek Vacacaí-Mirim and Ibicuí-Mirim rivers), located in the central region of Rio Grande do Sul/Brazil. Measures were taken with the radiometric spectroradiometer FieldSpec3 (spectral range of 400 to $900 \mathrm{~nm}$ and spectral resolution ranging from $3 \mathrm{~nm}$ ), the 


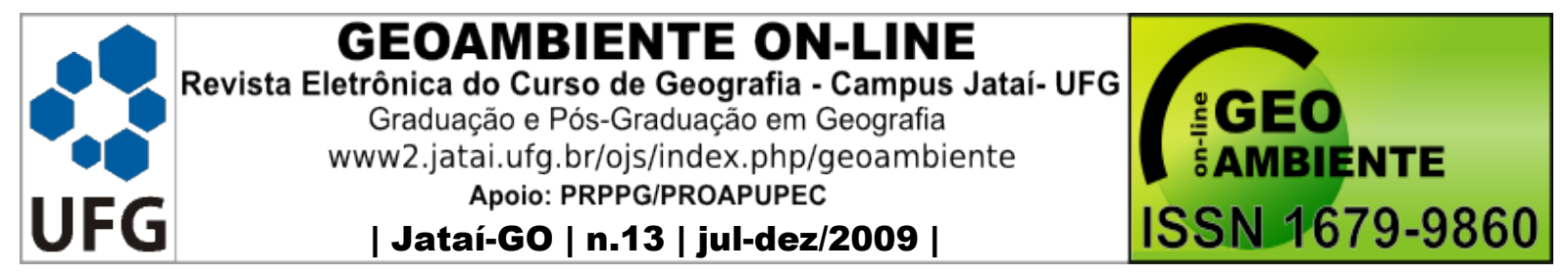

collections were performed on days 11/30/2007 and 12/07/2007. Concentrations of TDS influenced their reflectance (low albedo). Due to the high concentration of organic matter on the Vacacaí-Mirim $(23.35 \mathrm{mg} / \mathrm{l})$ is river surface, it presented a range of green wavelength (between $500 \mathrm{~nm}$ and $600 \mathrm{~nm}$ ) most expressive reflectance values than the watershed of Cadena Creek (9.65mg/l) and Ibicuí-Mirim River (2.55mg/l).

Key words: spectral reflectance, TSS, watershed, radiometry.

\section{1 - Introdução}

A reflectância da água é condicionada por diversos fatores, dentre eles pode-se destacar a concentração do total de sólidos em suspensão (TSS), concentração de clorofila e concentração de carbono orgânico dissolvido.

Em estudos de alvos terrestres por Sensoriamento Remoto, a reflectância da energia eletromagnética na superfície da terra é normalmente modelada como um evento bidimensional de espalhamento simples. Entretanto, quando o alvo se constitui em ambientes aquáticos, a modelagem se torna bem mais complexa.

O comportamento espectral da água é resultado dos processos de absorção e espalhamento da radiação no seu interior, e a radiação detectada pelo sensor fornece informações sobre características físico-químicas e biológicas da região estudada (CABRAL, 2003). Os trabalhos de comportamento espectral da água baseiam-se na aquisição simultânea de dados espectrorradiométricos e dados in situ de parâmetros de qualidade da água e concentram-se, principalmente, na faixa espectral correspondente à radiação fotossinteticamente ativa, entre 350 e $700 \mathrm{~nm}$. De um modo geral, a reflectância da água limpa diminui com o aumento dos comprimentos de onda. Verificam-se as maiores reflectâncias na região do visível, mais especificamente, nos comprimentos de onda do azul e verde, decrescendo gradualmente na direção do infravermelho, limitando-se os estudos de qualidade da água ao espectro visível (ROBERT et al, 1995).

A espectrorradiometria de campo é uma técnica de sensoriamento remoto que pode ser utilizada em diversos experimentos para obtenção de medidas da energia refletida, em diferentes faixas de comprimento de onda do espectro eletromagnético (HENDERSON e BADHWAR, 1984 apud RUDORFF, 2006). A grande vantagem do sensoriamento remoto é que tais medidas podem ser realizadas tanto próximas à superfície, em pequenas áreas, quanto do espaço aéreo, para observação detalhada de grandes regiões. 


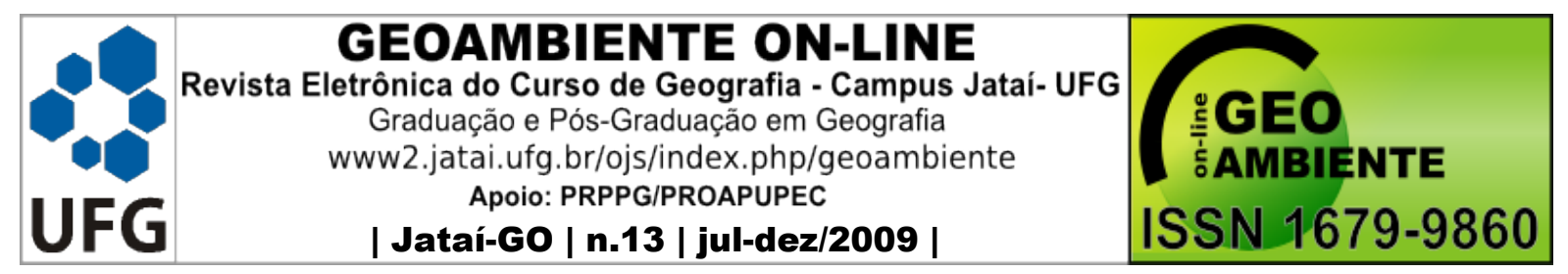

Na Figura 1 observa-se o processo na trajetória da radiação solar, desde a sua entrada na atmosfera, passando pela interface ar/água, sua interação com a coluna d’água, e seu caminho em direção ao sensor.

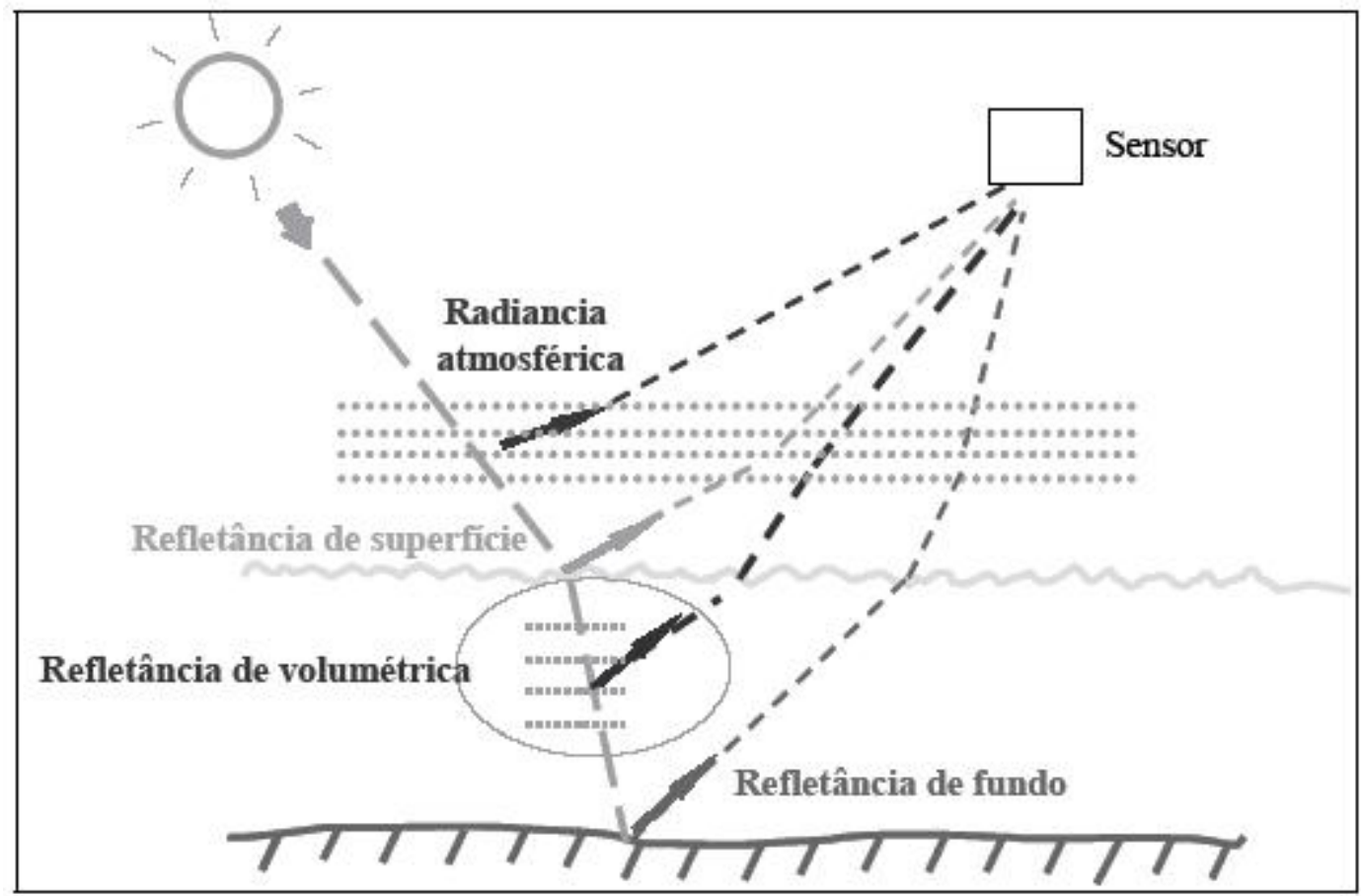

Figura 1 - Processos na trajetória da radiação solar. Fonte: Barbosa, 2005

A pesquisa teve como objetivo avaliar a reflectância espectral dos corpos d'água de três sub-bacias (arroio Cadena e dos rios Vacacaí-Mirim e Ibicuí-Mirim) e comparar com o TSS, localizadas na região central do Rio Grande do Sul/Brasil.

\section{2 - Fundamentação Teórica}

\subsection{Radiação Eletromagnética}

A capacidade de um objeto de refletir a energia radiante indica a sua reflectância, enquanto que a capacidade de absorver energia radiante é indicada pela sua absortância e, da mesma forma, a capacidade de transmitir energia radiante é indicada pela sua transmitância. Certamente um objeto escuro e opaco tem um valor baixo para a reflectância, alto para a absortância e nulo para a transmitância. A reflectância, absortância e a transmitância costumam ser expressas em percentagem (ou por um número entre 0 e 1) (STEFFEN e MORAES, 1993). 


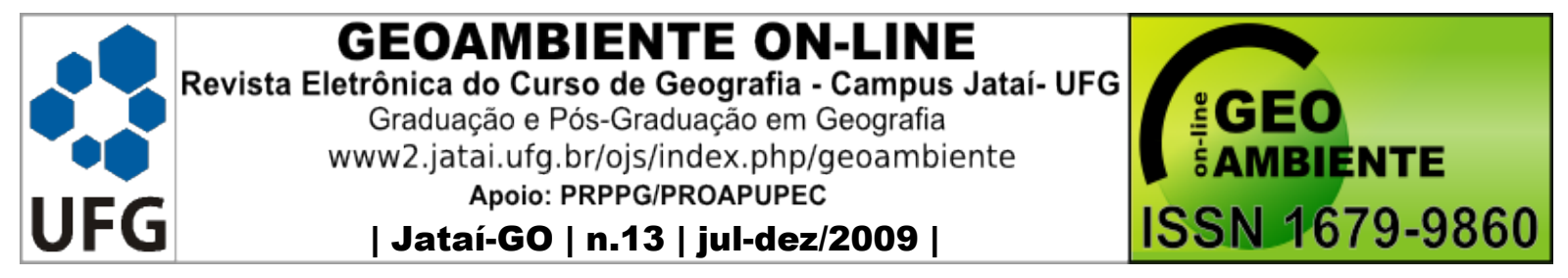

No processo de interação da radiação com um alvo, esta pode ser mensurada e analisada por técnicas de radiometria. As quantidades de energia envolvidas são denominadas grandezas radiométricas e são medidas em campo ou laboratório utilizando radiômetros. Destas grandezas, a fundamental é a energia radiante (Q), a partir do qual são derivadas as demais grandezas, como: radiância $(\mathrm{L})$, irradiância $(\mathrm{E})$, fluxo radiante $(\phi)$, exitância $(\mathrm{M})$, intensidade radiante (I) (STEFFEN e MORAES, 1993).

\subsection{Comportamento Espectral da Água}

A reflectância espectral de um corpo d'água depende das propriedades espectrais de seus componentes. Os componentes de um volume d'água que afetam seu comportamento espectral podem ser classificados em: pigmentos e complexos protéicos responsáveis pela fotossíntese, substâncias orgânicas dissolvidas, e material particulado em suspensão (BRICAUD e SATHYENDRANATH, 1995 apud CABRAL et al, 2003). Os principais responsáveis pelo espalhamento da radiação na água são as partículas suspensas como bactérias, células dos fitoplânctons e os detritos orgânicos e inorgânicos, enquanto os principais absorvedores da radiação são os pigmentos fotossintéticos, os detritos orgânicos e a matéria orgânica.

Os corpos d'água se distinguem também, dos demais alvos por apresentarem, em geral, baixas porcentagens de reflectância, o que implica em baixas radiâncias e, portanto, baixa probabilidade de que as diferenças detectadas pelos sensores estejam acima do ruído do sensor, para a maioria dos sensores de primeira e segunda geração e para a maioria dos sensores de alvos terrestres, como é o caso dos sensores TM/Landsat e HRV/SPOT (NOVO e PONZONI, 2001).

A maior parte do fluxo incidente sobre a água pura não é refletido, como ocorre no solo e na vegetação, mas sim absorvido ou transmitido. Nos comprimentos de onda do visível, pouca luz é absorvida, uma pequena quantidade é refletida e a maior parte é transmitida. MOREIRA (2003) destaca que a água no estado líquido absorve a radiação eletromagnética em comprimentos de onda menores que $380 \mathrm{~nm}$ e maiores do que $700 \mathrm{~nm}$ e que, mesmo nessa faixa intermediária, a reflectância da água é relativamente pequena, ultrapassando pouco mais de 5\%. A água pura tem uma resposta espectral particular, a reflectância é elevada no intervalo espectral correspondente à luz azul, diminui no verde, é fraca no vermelho e é quase nula no infravermelho próximo (ROBIN 1995, apud LIMA et al, 2005), pois como não ocorre 


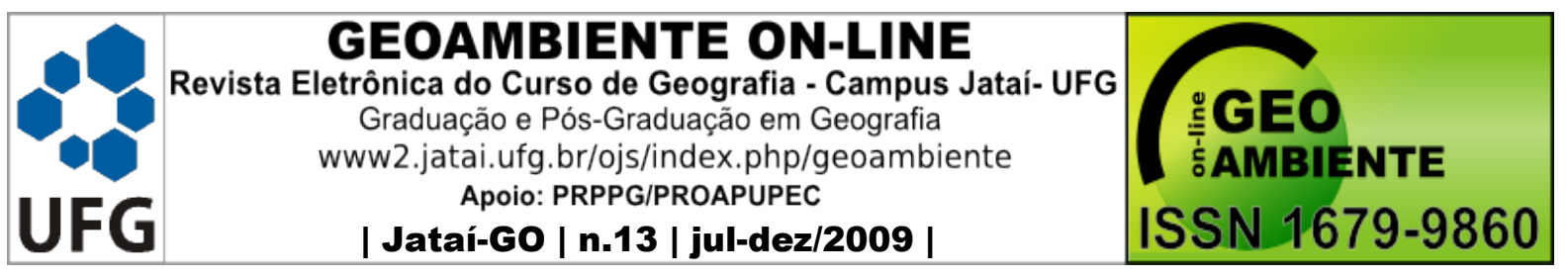

a presença de matéria orgânica ou sólidos em suspensão, a água absorve toda a radiação do infravermelho próximo incidente (JENSEN 2000, apud LIMA et al, 2005).

A porção relativa da radiância detectada pelo sensor irá variar conforme a geometria de visada, e as propriedades ópticas inerentes e aparentes da água (NOVO et al., 1989). As diferenças de abordagem do alvo água fazem com que a metodologia de aquisição de dados, a nomenclatura, os conceitos utilizados, entre outros, sejam muito específicos.

MOREL e PRIEUR (1977) apud BARBOSA (2005), estudando uma grande variedade de tipos d’água, classificou-as a partir da relação concentração de pigmentos/coeficiente de espalhamento em dois tipos: a concentração de clorofila é muito alta em relação ao coeficiente de espalhamento; a concentração de partículas inorgânicas é muito alta em relação à concentração de pigmentos.

Segundo NOVO e PONZONI (2001), a absorção de luz no meio aquático é decorrente da presença de quatro componentes básicos: a própria água, substâncias dissolvidas na água (substância amarela ou matéria orgânica), biota fotossintetizadora (fitoplâncton e macrófitas quando presentes) e partículas não vivas (partículas orgânicas mortas e partículas inorgânicas). As presenças de partículas orgânicas e inorgânicas na água também aumentam o seu coeficiente de absorção. Essas partículas em geral apresentam espectro de absorção semelhante ao da matéria orgânica, mas sua magnitude é bem menor, variando entre $0,3 \mathrm{~m}^{-1} \mathrm{a}$ 1,5 $\mathrm{m}^{-1} \mathrm{em}$ condições de águas bastante túrbidas. A maioria das plantas possui clorofilas $a, b$, $c$ e mais raramente $d$. A clorofila que ocorre em maior abundância é a clorofila $a$ (LONDE et al., 2005). A razão entre a concentração de clorofila $a$ e $b$ varia também de espécie para espécie, podendo atingir valores mínimos em torno de $1,0 \mathrm{mg} / \mathrm{L}$ em espécies marinhas e até 6,0 mg/L como o encontrado para a Euglenofita (NOVO, 2001).

A clorofila $a$ atua como centro de reação fotossintética e possui dois picos de absorção um no azul, em $433 \mathrm{~nm}$, chamado "Soret" e outro no vermelho, em $686 \mathrm{~nm}$, chamado "alpha" (KIRK, 1994). Enquanto a clorofila $a$ absorve fracamente entre 450 e $650 \mathrm{~nm}$ a clorofila $b$ tem o efeito de aumentar a absorção, tanto para o lado dos comprimentos de onda mais longos quanto para os mais curtos.

A transparência da água varia de alguns centímetros a dezenas de metros. Esta região da coluna d'água chama-se zona eufótica, varia com a capacidade da água em atenuar a radiação subaquática e corresponde à profundidade onde a intensidade da radiação solar equivale a 1\% daquela que atinge a superfície (ESTEVES, 1998). 


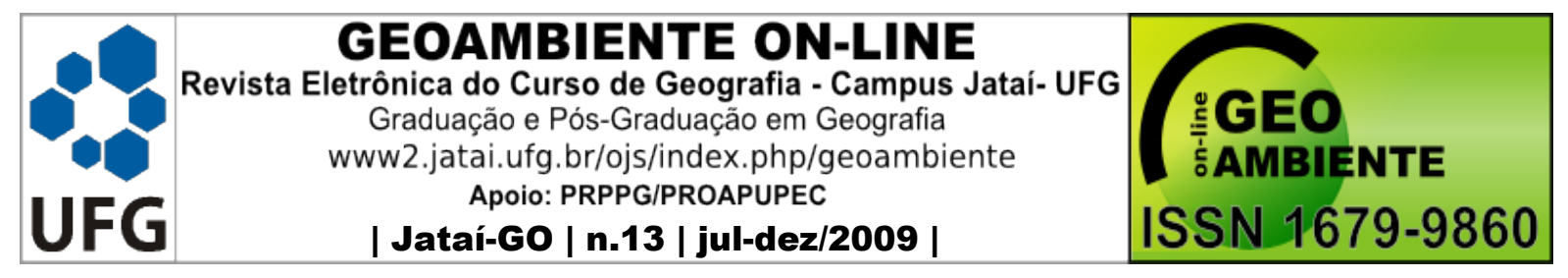

Embora a profundidade do disco de Secchi não forneça dados sobre a qualidade e a quantidade de radiação solar, pode-se utilizá-la para o cálculo indireto do coeficiente vertical de atenuação $(\mathrm{k})$.

$$
\mathrm{k}=\frac{1,7}{\mathrm{Zds}}
$$

Onde:

$\mathrm{k}=$ coeficiente de atenuação vertical da radiação

$1,7=$ constante calculada

$\mathrm{Zds}=$ profundidade do disco de Secchi, em metros.

A cor da água e a quantidade de sólidos em suspensão têm forte participação no comportamento espectral da água. A cor da água representa o metabolismo aquático (PEREIRA FILHO, 1991). A Figura 2 mostra a diferença na resposta espectral entre um rio de água limpa e um rio de água turva.

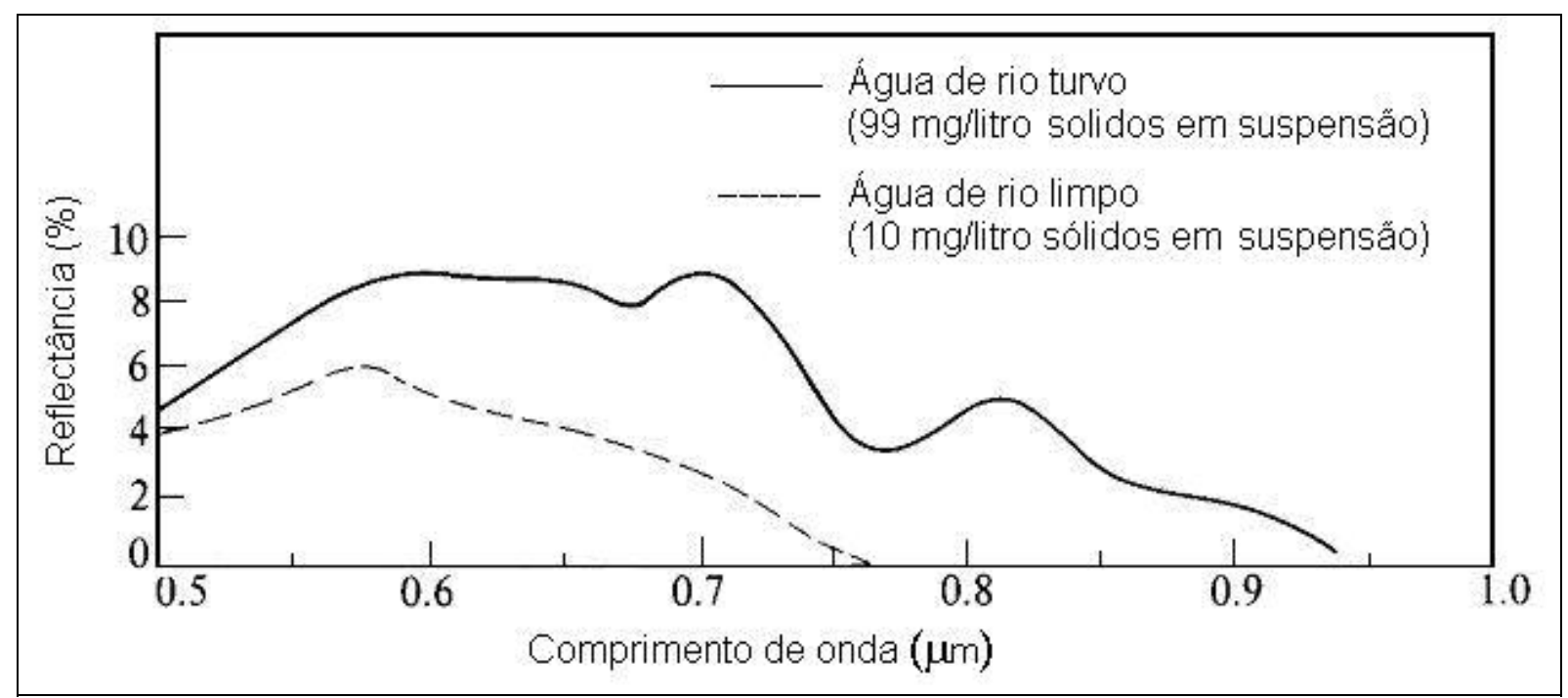

Figura 2 - Comportamento espectral da água em rios turvo e limpo. Fonte: Adaptado de Lillesand e Kiefer (1987)

Como o espalhamento no meio aquático é provocado pela própria água e pelas partículas vivas e não vivas em suspensão na água. A forma geral do espalhamento pela água caracteriza-se por uma redução exponencial do espalhamento em direção a comprimentos de ondas mais longos. Como o espalhamento é proporcional também ao número de partículas no 


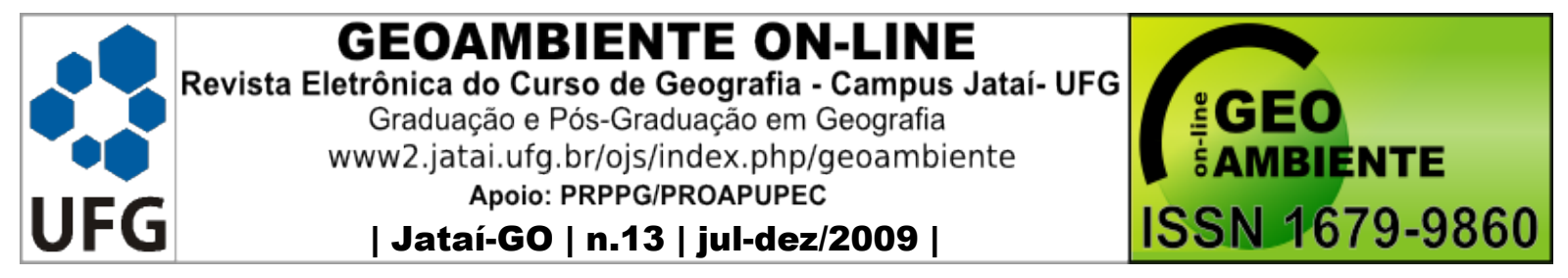

meio aquático, em geral, partículas finas resultam em maiores coeficientes de espalhamento (NOVO e PONZONI, 2001).

\section{3 - Materiais e Procedimentos Metodológicos}

\subsection{Descrição da área}

As três sub-bacias estão inseridas na mesorregião Centro Ocidental Rio-Grandense. As sub-bacias do arroio Cadena e do rio Vacacaí-Mirim, estão localizadas no município de Santa Maria-RS, e possuem área aproximada de 4883,40 ha e 6367,39 ha de área total, respectivamente. Já a sub-bacia do rio Ibicuí-Mirim está localizado entre os municípios de Santa Maria, Itaara e São Martinho da Serra - RS, possuindo uma área de aproximadamente 15955,28 ha.

O rio Vacacai-Mirim e o arroio Cadena pertencem à bacia do rio Vacacaí que por sua vez faz parte do rio Jacuí. O rio Ibicuí-Mirim faz parte do rio Ibicuí que é o principal afluente do rio Uruguai. Sua formação dá-se na junção do Ibicuí-Mirim com o rio Santa Maria, na região sudoeste do Rio Grande do Sul. Além disso, oferece a possibilidade de ligação com a bacia do Jacuí, formando uma via navegável que atravessará o estado do Rio Grande do Sul de leste a oeste. Portanto, a área de estudo localiza-se em um divisor de águas de dois importantes sistemas hídricos do RS.

\subsection{Materiais}

Espectrorradiômetro FieldSpec3, fabricado pela empresa Analytical Spectral Devices. Esse espectrorradiômetro possui campo de visada de $25^{\circ}$, intervalo espectral de 350 a 2500 $\mathrm{nm}$, resolução espectral variando de 3 a $10 \mathrm{~nm}$ e tempo para aquisição de dados de aproximadamente 1/10 de segundo por espectro. O fator de reflectância foi obtido utilizandose como superfície lambertiana a placa Spectralon 11. O controle, registro e processamento dos dados medidos foram feitos com o auxílio de um microcomputador portátil. Apesar desta configuração a faixa espectral utilizada nesta pesquisa ficou restrita de 400 a $900 \mathrm{~nm}$, devido ao alto nível de ruído para comprimentos de onda localizados fora desta faixa.

\subsection{Procedimentos Metodológicos}

O espectrorradiômetro FieldSpec3 foi empregado para a aquisição dos dados espectrais da água nos dias 30/11/2007 e 07/12/2007. Para cada ponto de coleta (Figura 3) o 


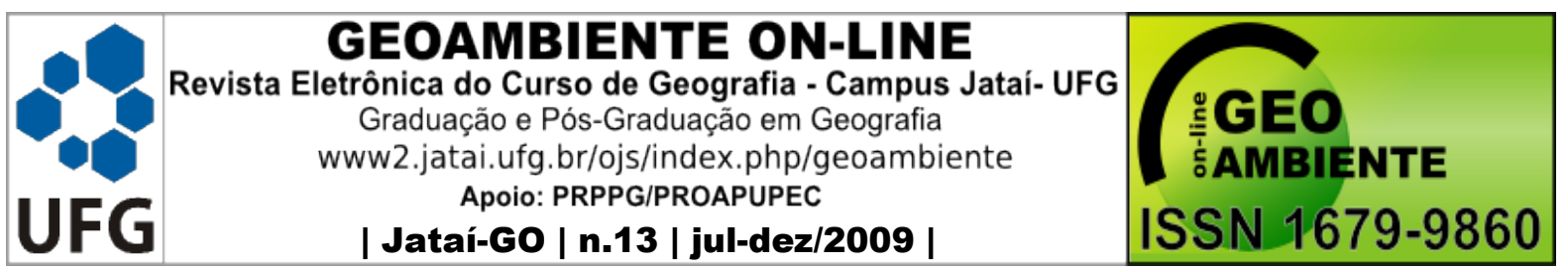

radiômetro foi calibrado com a placa Spectralon 11. A altura média para as coletas de radiometria nos pontos foi de 2 metros.

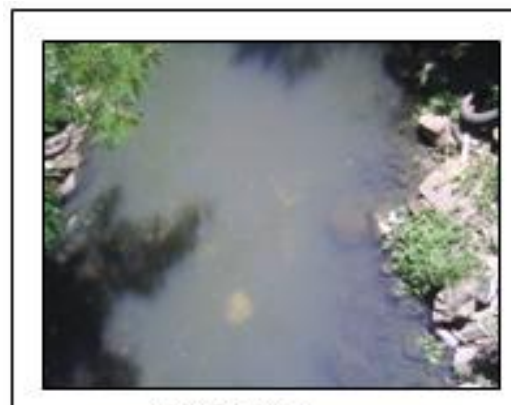

(a) Cadena

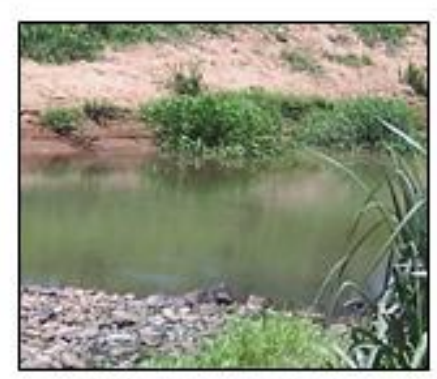

(b) Vacacai-Mirim

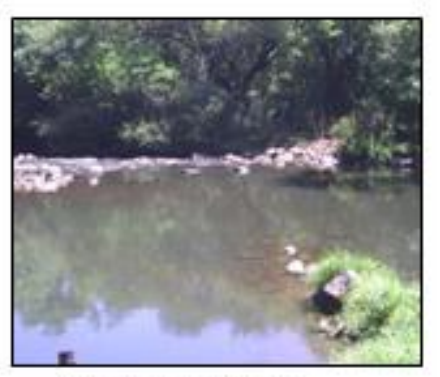

(c) Ibicui-Mirim

Figura 3 - Pontos de aquisição dos dados com o Espectrorradiômetro

O procedimento de coleta de dados espectrais seguiu metodologia proposta por MILTON (1987), ou seja, preservou ao máximo a igualdade de condições de iluminação e de superfície de água. A importância de se fazer às medidas sem a presença de ventos, e devido ao fato deste ser um dos efeitos mais importantes na degradação das informações espectrais em coletas de campo (PEREIRA FILHO et al., 2002). O espectrorradiômetro foi posicionado em cada ponto amostral com eixo de visada de $45^{\circ}$ de inclinação em relação à vertical e de $90^{\circ}$ de azimute em relação a posição do sol, nestas condições evitou-se o efeito da reflectância especular da água.

\section{4 - Resultados e Discussão}

O comportamento espectral do arroio Cadena e dos rios VacacaíMirim e Ibicuí-Mirim para duas datas de coletas (30/11/2007 e 0712/2007) pode ser observado nas Figuras 4 e 5 respectivamente.

Observa-se nas Figuras 4 e 5, que o rio Vacacaí-Mirim apresentou picos de reflectância nos comprimentos de onda na faixa do verde do espectro eletromagnético $(570 \mathrm{~nm})$ para as duas coletas realizadas, sendo mais expressiva para a segunda coleta (07/12/2007). Este rio apresenta, como observado em campo, grande quantidade de pigmentos fotossintetizantes em sua superfície. Também ocorreu pico de reflectância em $720 \mathrm{~nm}$ e na faixa de 770 a $810 \mathrm{~nm}$, mas com menor intensidade devido provavelmente a presença de 


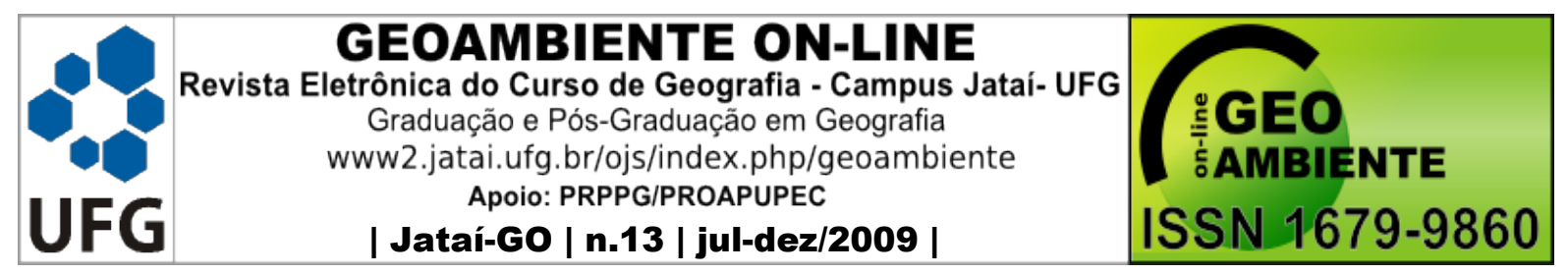

sólidos em suspensão, a rugosidade da superfície da água e matéria orgânica presente neste rio.

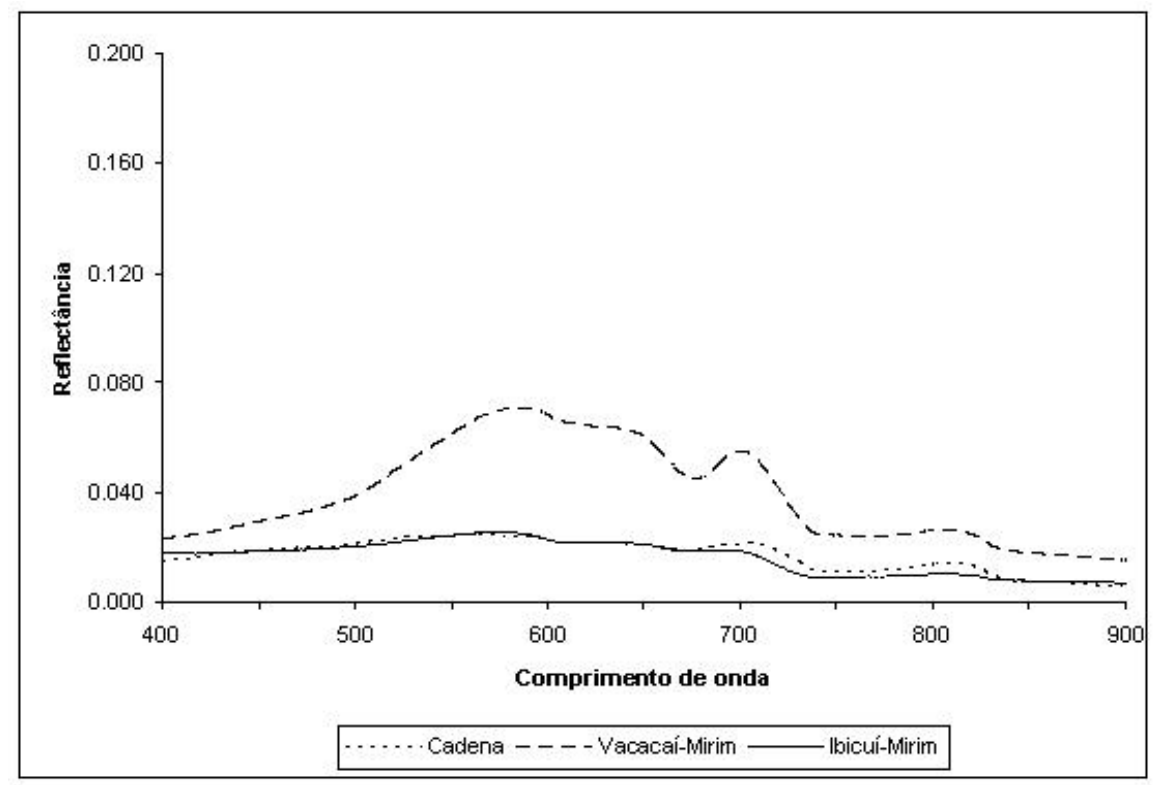

Figura 4 - Reflectância da água dia 30/11/2007

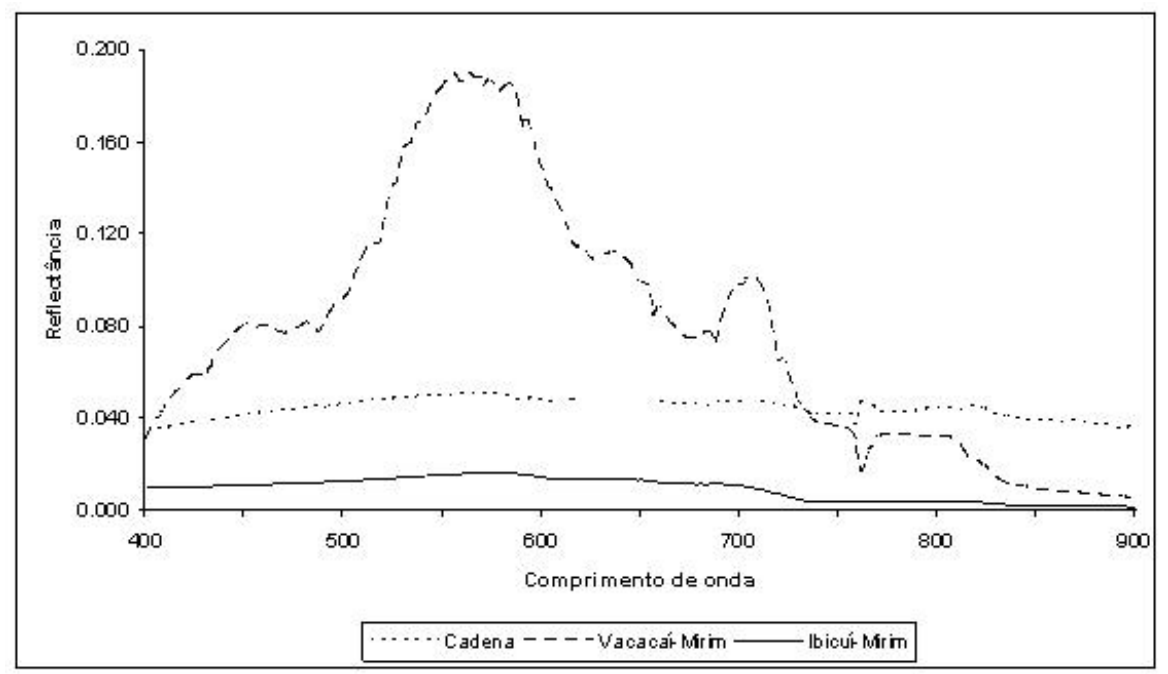

Figura 5 - Reflectância da água ia 07/12/2007

O rio Ibicuí-Mirim para as coletas realizadas nos dias 30 de novembro (Figura 4) e 7 de dezembro (Figura 5) apresentou variação da reflectância inferior a $0,04 \%$, isto está relacionado a baixa concentração de TSS e a alta transparência neste rio (Quadro 1), possui média de 2,63 mg/L, enquanto que o Cadena e o Vacacaí-Mirim possuem 7,547 mg/L e $17,697 \mathrm{mg} / \mathrm{L}$, respectivamente. A baixa concentração de TSS também exerceu influência no albedo, principalmente das amostras do rio Ibicuí-Mirim que apresentou o menor albedo em 


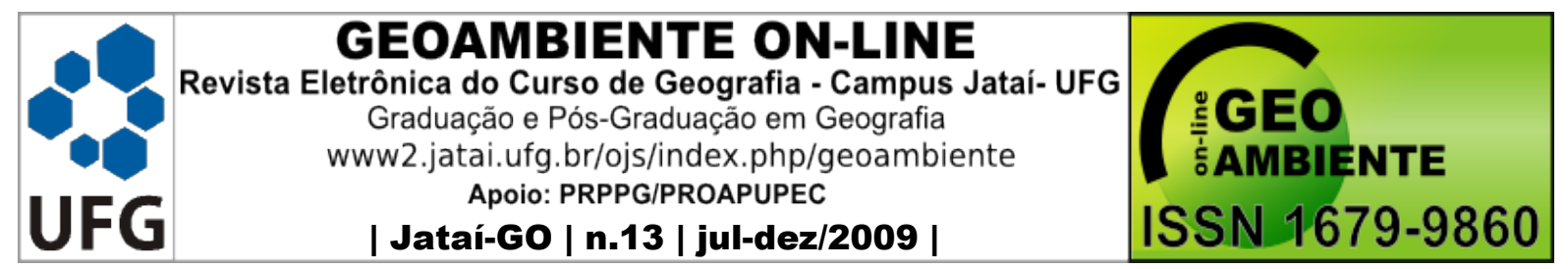

todas, ao contrario do rio Vacacaí-Mirim que possui maior albedo em todas as amostras, por conter maior concentração de TSS.

Quadro 1 - Transparecia (DS) e TSS nas sub-bacias

\begin{tabular}{|c||r|r||r|r||r|r|}
\hline \multirow{2}{*}{$\begin{array}{c}\text { Período de } \\
\text { Coleta }\end{array}$} & \multicolumn{2}{|c||}{ Arroio Cadena } & \multicolumn{2}{c||}{ Rio Vacacaí-Mirim } & \multicolumn{2}{c|}{ Rio Ibicuí-Mirim } \\
\cline { 2 - 7 } & $\begin{array}{c}\text { Transparência } \\
\text { (DS) cm }\end{array}$ & TSS mg/l & $\begin{array}{c}\text { Transparênci } \\
\text { a } \\
\text { (DS) cm }\end{array}$ & TSS mg/l & $\begin{array}{c}\text { Transparência } \\
\text { (DS) cm }\end{array}$ & TSS mg/l \\
\hline $30 / 11 / 2007$ & 60 & 9,65 & 62,5 & 23,35 & 115 & 2,55 \\
\hline $7 / 12 / 2007$ & 60 & 6,90 & 40,0 & 6,20 & 138 & 3,00 \\
\hline
\end{tabular}

No comprimento de onda de $675 \mathrm{~nm}$, que compreende a faixa do vermelho, observa-se que para as duas coletas (Figuras 4 e 5) houve feições de absorção expressivas para o rio Vacacaí-Mirim e com menor intensidade para o arroio Cadena, devido à absorção de clorofila. Em relação ao efeito provocado na faixa azul, observa-se que ocorreu aumento da reflectância apenas para a amostra do rio Vacacaí-Mirim do dia 07/12/2007 (Figura 5), já para a primeira amostra (30/11/2007), não se verificou variações na reflectância, isto pode ter ocorrido pela presença de matéria orgânica que provoca absorção na faixa do comprimento de onda correspondente ao azul.

Verifica-se que na segunda coleta realizada no dia 07/12/2007 (Figura 5) nos comprimentos de onda entre $750 \mathrm{~nm}$ e $775 \mathrm{~nm}$, ocorreu certa semelhança entre os picos de reflectância e absorção, para o arroio Cadena e o rio Vacacaí-Mirim. Provavelmente estas semelhanças, ocorreram por interferência das condições climáticas e das concentrações de TSS no dia da coleta.

Podem-se comparar os resultados obtidos nesta pesquisa com os registrados por GITELSON et al. (2007), no qual avaliaram que a reflectância foi bastante variável ao longo da região espectral do visível.

As medidas de reflectância em campo são mais sujeitas a variabilidade dos fatores de aquisição.

O que pode ter caracterizado a reflectância na faixa do verde para as amostras coletas.As águas provindas da chuva juntamente com solo são relativamente ricas em nitrogênio que contribuem para a produção de fitoplâncton nas águas (RUDORFF et al, 2007). 


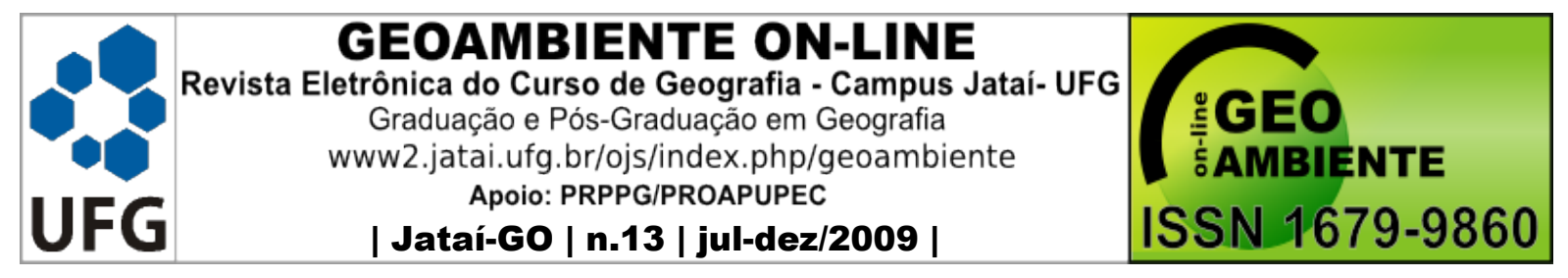

\section{5 - Conclusão}

A baixa reflectância para o rio Ibicuí-Mirim é resultado da baixa concentração dos componentes opticamente ativos, pois este apresenta baixas concentrações de TSS, elevada transparência, e a baixa concentração de matéria orgânica em sua superfície como pode ser observado em campo. A água do rio Vacacaí-Mirim por ser turva (elevadas concentrações de TSS) tem reflectância maior que a água do rio Ibicuí-Mirim, verificada in loco como mais limpa. Neste rio foi observado nos espectros de reflectância feições de absorção típicas da clorofila. Os níveis tróficos desse ambiente provavelmente estejam proporcionando este quadro.

Já a baixa reflectância do arroio Cadena, por estar no meio urbano apresenta características singulares, pois apesar de ser altamente poluído (suas margens apresentam grande quantidade de lixo e lançamento de esgoto sem tratamento) não apresentou concentrações elevadas de TSS o que pode ter contribuído a sua baixa reflectância, mas os picos observados principalmente na faixa correspondente ao verde, podem ter sido ocasionados pela presença de pigmentos fotossintetizantes oriundos da alta taxa de eutrofização do sistema aquático.

Todas as amostras apresentaram uma taxa de aumento em direção à faixa do verde (entre $500 \mathrm{~nm}$ e $600 \mathrm{~nm}$ ), onde atingiram seu máximo, com os valores mais elevados sendo encontrados para as amostras do rio Vacacaí-Mirim. Este comportamento, provavelmente, se deve à presença de TSS e clorofila, a qual exerce influencia na reflectância principalmente neste comprimento de onda (faixa do verde $-500 \mathrm{~nm}$ a $600 \mathrm{~nm}$ ).

\section{6 - Referências}

BARBOSA, C.C.F. Sensoriamento Remoto na Dinâmica da Circulação da Água do Sistema Planície de Curai/Rio Amazonas. Tese de Doutorado, INPE, São José dos Campos, 2005. Disponível em <http://www.dpi.inpe.br/teses/claudio/tese_claudio_barbosa.pdf $>$. Acesso em: $22 / 10 / 2007$.

CABRAL, J. B. P.; FERNANDES, L.A.; SCOPEL, I.; LOPES, R. M.; SOUSA, R. R.; FREITAS V. V.; MORAES R. S.; SILVA, S. A. Caracterização Geoambiental do Reservatório de Cachoeira Dourada - GO/MG (Fase - 1). X Simpósio Brasileiro de Geografia Física Aplicada, 2003. Disponível em < http://geografia.igeo.uerj.br/xsbgfa/cdrom/ eixo3/3.4/229/229.htm > acesso em 22/10/2007. 


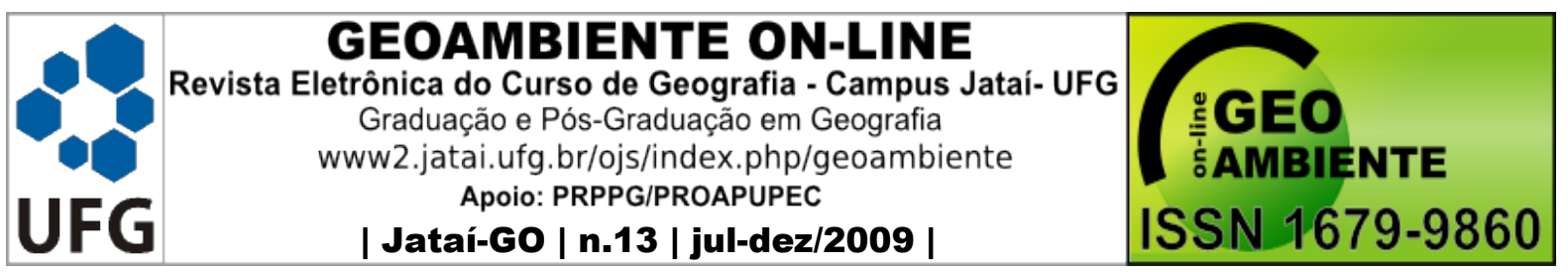

CHEN, Z.; CURRAN, P.J.; HANSOM, J.D. Derivative reflectance spectroscopy to estimate suspended sediment concentration. Remote Sensing of Environment, v.40, n.1, p.67-77, 1992. CHUVIECO, E. Fundamentos de Teledetección Espacial. Ediciones Rialp, S.A. Madrid, 1990.

CURRAN, P. J; NOVO, E.M.L.M. The relationship between suspended sediment concentration and remotely sensed spectral radiance: a review. Journal of Coastal Resources, v.4, p. 351-368, 1998.

EASTMAN, J.R. Idrisi version 32. Worcester : Clark University, 1993. 209p.

ESTEVES, F. A. Fundamentos de Limnologia. $2^{\circ}$ edição. Rio de Janeiro: Editora Interciência, 1998. 602p.

GITELSON, A. A.; SCHALLES, J. F.; HLADIK, C. M.. Remote chlorophyll-a retrieval in turbid, productive estuaries: Chesapeake Bay case study. Remote Sensing of Environment v.109, p.464-472, 2007

; M. N. MERZLYAK. Spectral reflectance changes associate with autumn senescence of Aesculus hippocastanum L. and Acer plataniodes L. leaves: Spectral features and relation to chlorophyll estimation. J. Plant Physiol. v.143, p.286-292, 1994.

KIRK, J. T. O. Light \& photosynthesis in aquatic ecosystems. 2nd ed. Cambridge: Cambridge University Press, 1994.

LILLESAND, T. M.; KIEFER, R. W. Remote sensing and image interpretation. 2. Ed. New York: J. Wiley, 1987, 850p.

LONDE, L. R.; NOVO, E. M. L. M.; CALIJURI, M. C. Avanços no estudo do comportamento espectral do fitoplâncton e identificação remota de algas. In: Simpósio Brasileiro de Sensoriamento Remoto, 12., 2005, Goiânia, INPE, 2005. p. 389 - 396.

LIMA, D. L.; GALO, M. L. B. T.; IMAI, N. N.. Aplicação do modelo de cores IHS na deteç̧ão de plantas aquáticas imersas. Anais XII Simpósio Brasileiro de Sensoriamento Remoto, Goiânia, Anais...Goiânia, SBSR, 2005. CD-ROM

MCCLUNEY, W.R.; Ocean Color Spectrum Calculations. Applied Optics, v.13, n.10, p.2422-2429, 1974.

MOREIRA, Maurício Alves. Fundamentos do Sensoriamento Remoto e Metodologias de Aplicação. São José dos Campos/SP: Instituto Nacional de Pesquisas Espaciais (INPE), 2003, $304 p$. 


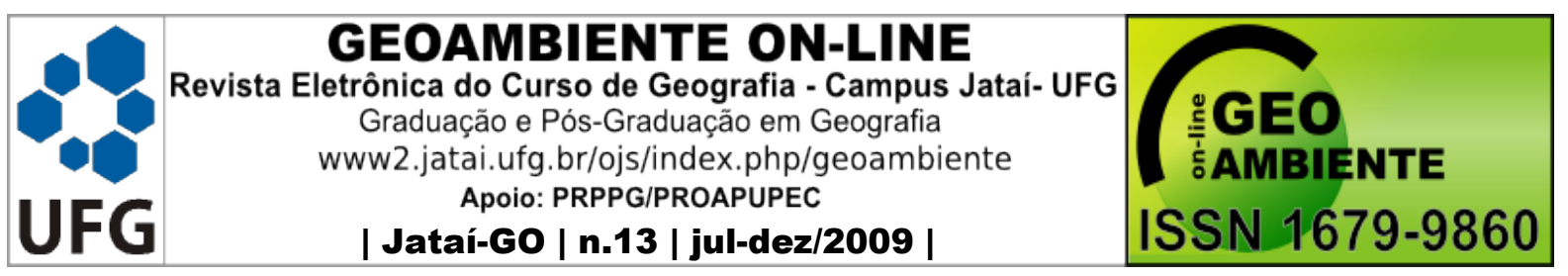

MILTON, E.J. Principles of field spectroscopy. International Journal of Remote Sensing, v.8, n.12, p.1807-1827, 1987.

MERTES, L. A. K.; SMITH, M. O.; ADAMS, J. B. Estimating Suspended Sediment Concentrations in Surface Waters of the Amazon River Wetlands from Landsat Images. Remote Sensing of Environment. v.43, p.281-301, 1993.

NOVO, E.M.L.M; PONZONI, F. J. Introdução ao Sensoriamento Remoto. Instituto Nacional de pesquisas Espaciais, Divisão de Sensoriamento Remoto, 2001. Disponível em < http://www.agro.unitau.br/sensor_remoto/apofla.pdf > acesso em 03/10/2007.

Comportamento espectral da água. In: MENEZES, P.R.; NETTO, J.S.M. (Org.) Sensoriamento remoto: reflectância dos alvos naturais. Brasília: UNB, 2001. p.203-222.

PEREIRA FILHO, W. Integração de dados de campo e sensoriamento remoto no estudo da influência das características da bacia de captação na concentração de sólidos em suspensão em reservatório: O exemplo de Tucuruí. 1991, 175p. Dissertação (Mestrado em Sensoriamento Remoto) Instituto Nacional de Pesquisas Espaciais - São José dos Campos, 1991.

Influência dos Diferentes Tipos de Uso da Terra em Bacias Hidrográficas sobre Sistemas Aquáticos da Margem Esquerda do Reservatório de Tucurui-Pará. 2000. 138p. Tese (Doutoramento em Geografia Humana)-Universidade de São Paulo, São Paulo, 2000.

; NOVO, E. M. L. M. Limnological variables and macrophyte infestation in Tucuruí reservoir - Pará - Brazil. In: International Geoscience and Remote Sensing Symposium, 2002, Toronto. 2002.

QUEIROZ, J. E. R.; GOMES, H. M. Introdução ao Processamento Digital de Imagens. RITA, v.8, n.1, 2001.

ROBERT, A.; KIRMAN,C.; LESACK, L. Suspended sediment concentration estimation from multi-spectral video imagery. International Journal Remote Sensing, v.16, p.2439-2455, 1995. ROSA, R. Introdução ao Sensoriamento Remoto. 5 ed., Uberlândia, UFU, 2003.

RUDORFF, C. M. Estudo da Composição das Águas da Planície Amazônica por Meio de Dados de Reflectância do Sensor Hyperion/EO-1 e de Espectrorradiômetro e Campo Visando a Compreensão da Variação Temporal dos seus Constituintes Opticamente Ativos. Dissertação de Mestrado em Sensoriamento Remoto. INPE, São José dos Campos, 2006. 


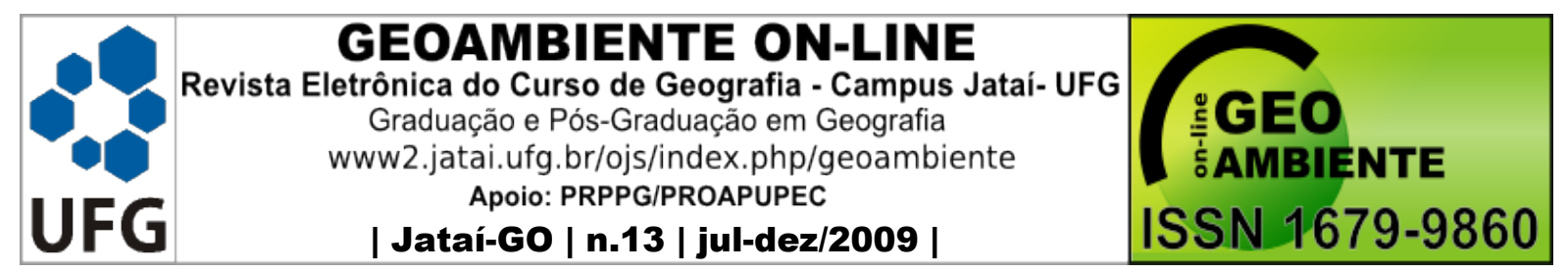

. et al. Análise derivativa de dados hiperespectrais medidos em nível de campo e orbital

para caracterizar a composição de águas opticamente complexas na Amazônia. Acta Amazônica. v.37, n.2, p.269 - 280, 2007.

STEFFEN, C. A.; MORAES, E. C. SPECTRON SE-590 - Manual de Referencia. In: VII Simpósio Brasileiro de Sensoriamento Remoto, Curitiba, Anais... Curitiba, SBSR, 1993. CDROM. 